\title{
Insuficiencia arterial aguda severa vinculada a ergotismo
}

\author{
Gastón Aguirre*, Federico Verga ${ }^{\dagger}$
}

\section{Resumen}

El ergotismo es un síndrome clínico poco frecuente pero potencialmente letal vinculado a la intoxicación aguda o crónica con el uso de alcaloides del ergot en el tratamiento de la migraña. Se caracteriza por un vasoespasmo severo generalizado que puede generar isquemia periférica o visceral y conducir a disfunción orgánica múltiple y muerte. Existen numerosos fármacos de metabolismo hepático que pueden alterar la metabolización de la ergotamina pudiendo alcanzar concentraciones tóxicas incluso a bajas dosis. Presentamos el caso de un paciente infectado con virus de la inmunodeficiencia humana bajo tratamiento antirretroviral que incluía inhibidores de la proteasa y que se había automedicado con ergotamina. El paciente presentó posteriormente sintomatología sensitivo motora deficitaria de miembros superiores e inferiores, acompañada de elementos de hipoperfusión distal severa. Se solicitó Doppler arterial que evidenció vasoespasmo de ejes arteriales de miembros. Se realizó diagnóstico de ergotismo secundario a la asociación de ergotamina - ritonavir, ingresando a cuidados intensivos. Se inició tratamiento en base a suspensión de ambos fármacos, vasodilatación arterial con nitroprusiato y antiagregación con ácido acetilsalicílico. En relación con este caso se presenta una revisión del mecanismo de toxicidad de la ergotamina, sus interacciones farmacológicas, así como diagnóstico y tratamiento disponibles para esta patología.

Palabras clave: ERGOTISMO

INSUFICIENCIA ARTERIAL AGUDA

Key words: $\quad$ ERGOTISM

ACUTE ARTERIAL INSUFFICIENCY

\footnotetext{
* Residente del servicio de terapia intensiva del CASMU. Montevideo, Uruguay.

† Médico intensivista del servicio de terapia intensiva del CASMU. Montevideo, Uruguay.

Los autores declaran no tener conflicto de intereses.

Recibido: 29/9/17

Aceptado: $16 / 2 / 18$
} 


\section{Introducción}

El ergotismo es una causa rara de insuficiencia arterial causada por la intoxicación aguda o el uso crónico de los alcaloides derivados del ergot, o ambos, entre los que se encuentran la ergotamina y bromocriptina indicados en el tratamiento de la cefalea migrañosa y la hiperprolactinemia respectivamente. Se encuentran ampliamente distribuidos y disponibles sin prescripción médica en nuestro medio. $\mathrm{Al}$ asociarlos con fármacos que afectan su metabolismo hepático, inhibiendo el citocromo P-450, como es el caso de ritonavir, pueden alcanzar concentraciones tóxicas, incluso a bajas dosis. Afecta con más frecuencia las arterias de pequeño y mediano calibre de las extremidades, aunque también puede afectar a grandes vasos y generar sintomatología diversa debida a isquemia en cualquier sector del organismo, pudiendo generar consecuencias devastadoras ${ }^{(1)}$.

Presentamos el caso de un paciente infectado con virus de la inmunodeficiencia humana (VIH) en tratamiento con antirretrovirales (TARV) que incluyen inhibidores de la proteasa y que se había automedicado con ergotamina. Se realizó diagnóstico de ergotismo secundario a la asociación de ergotamina más inhibidores de la proteasa. En relación con este caso se presenta una revisión del mecanismo de toxicidad del fármaco, interacciones, farmacocinética, diagnóstico y tratamiento disponibles para esta patología.

\section{Caso clínico}

Hombre de 26 años con antecedentes de VIH diagnosticado hace tres años, en tratamiento con TARV que incluía lopinavir, ritonavir, lamivudina y tenofovir (carga

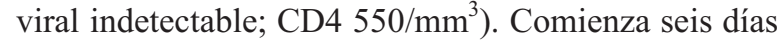
previos al ingreso con malestar general y mialgias, agregando parestesias de miembros inferiores (MMII), disminución de fuerza a nivel distal, coloración violácea y frialdad de manos. Consulta en emergencia, donde

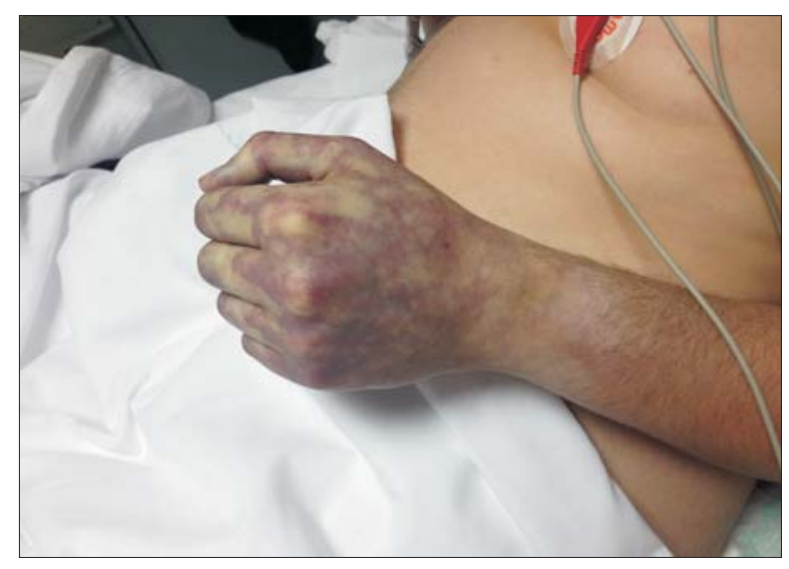

Figura 1. Acrocianosis del miembro superior izquierdo. se solicita analítica básica que no muestra alteraciones, se indica pentoxifilina y se otorga alta. Presenta mala evolución, peoría progresiva de la sintomatología en miembros, reconsulta 24 horas después en emergencia desde donde se solicita ingreso a la unidad de cuidados intensivos (UCI) con planteo de shock séptico, basado en los elementos de hipoperfusión distal.

Ingresa a UCI lúcido, eupneico, normotenso y apirético; presentado dolor y parestesias de MMII. A nivel de piel y mucosas se destacaba vasculopatía periférica con frialdad, cianosis y livideces de manos y pies (figuras 1 y 2). Ausencia de pulso radial pedio y tibial posterior. ECG: taquicardia sinusal de $120 \mathrm{cpm}$, sin otros trastornos a destacar. Reinterrogado, manifiesta ingesta de cuatro comprimidos con $400 \mathrm{mg}$ de ibuprofeno, $100 \mathrm{mg}$ de cafeína y $1 \mathrm{mg}$ de ergotamina tartrato (Perifar migra $®)$, por cefalea. Primera dosis 12 horas previas del comienzo del cuadro, refiriendo ser consumidor habitual de dicho fármaco. Se solicita Doppler arterial que evidencia ejes arteriales de MMII y superiores permeables pero de calibre disminuido, luz filiforme y flujos monofásicos en toda su extensión; resultando estos hallazgos compatibles con ergotismo generalizado. Ecocardiografía transtorácica normal.

Se suspende transitoriamente el TARV, se comienzan vasodilatadores, inicialmente nitroglicerina y luego nitroprusiato de sodio, se indica ácido acetilsalicílico y heparina de bajo peso molecular. Se repite Doppler arterial a las 72 horas, evidenciando mejoría de flujos arte-

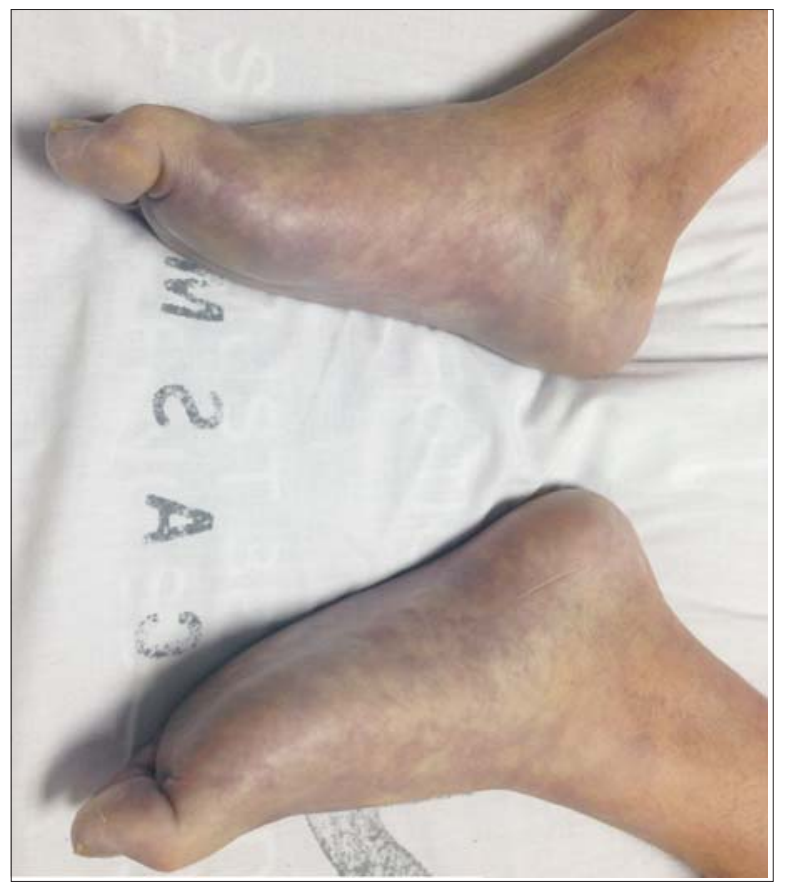

Figura 2. Acrocianosis de miembros inferiores. 


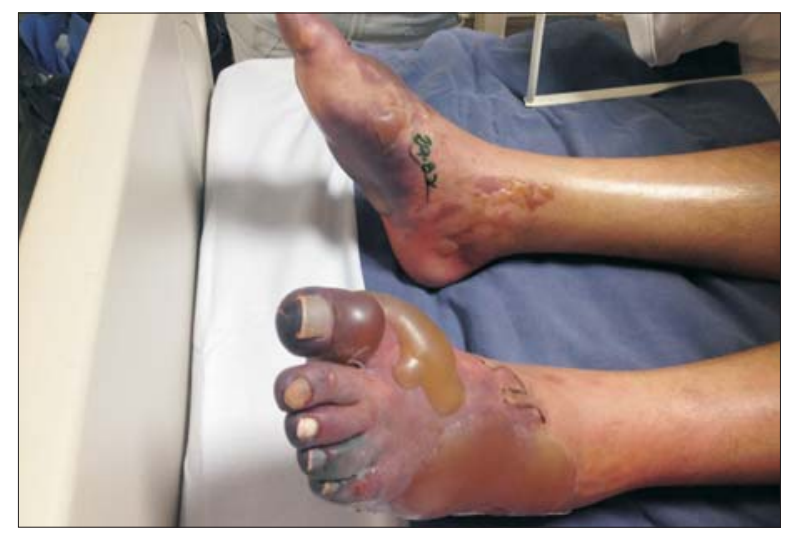

Figura 3. Necrosis distal con presencia de flictenas, arteriopatía evolucionada.

riales. Se mantiene el nitroprusiato de sodio por 72 horas, continuándose en forma posterior con nifedipina, doxazosina y pentoxifilina. Como complicación presenta rabdomiólisis con cifras máximas de creatininfosfoquinasa de $15.575 \mathrm{U} / \mathrm{ml}$, realizándose nefroprotección con suero bicarbonatado, no presentando injuria renal aguda, trastornos ácido base, ni disionías severas.

A las 96 horas de ingresado reinstala cianosis de MMII, repitiéndose Doppler arterial que evidencia obstrucción de tibial anterior y posterior bilateral. Valorado por cirujano vascular, realiza dilatación neumática con Fogarty, previo consentimiento informado, con Doppler de control que evidencia flujo distal. Mala evolución posterior agrega edema, parestesias y flictenas en MMII, delimitándose zonas de necrosis. Presenta pico febril, leucocitosis $15.000 / \mathrm{mm}^{3}$, se realiza relevo bacteriológico, iniciándose tratamiento antibiótico con piperacilina - tazobactam y vancomicina empíricamente, desarrollando en cultivo de flictena Proteus mirabilis sensible al tratamiento instaurado.

Evoluciona favorablemente, recuperando parcialmente perfusión distal y motilidad fina. Presenta úlceras isquémicas distales en ambos MMII, con flictenas y áreas necróticas (figura 3). No presenta disfunciones orgánicas, corrección de rabdomiólisis, se otorga alta a sala de cuidados convencionales luego de 12 días de internación en UCI. En sala, luego de delimitar área de necrosis, se realiza amputación de cuarto y quinto dedo de pie derecho, otorgándose alta a domicilio con alteración de la motricidad fina de miembros superiores.

\section{Discusión}

En el año $600 \mathrm{aC}$ aparece como primer registro, en una plancha de arcilla asiria, la contaminación del centeno y otros granos relacionada con el hongo Claviceps purpurea, también llamado cornezuelo del centeno. Este hon-
Tabla 1. Inhibidores de citocromo P-450 isoenzima CYP-3 A4.

\begin{tabular}{ll}
\hline Macrólidos & Antimicóticos \\
\hline Eritromicina & Itraconazol \\
Azitritromicina & Ketoconazol \\
\hline Inhibidores de la proteasa & Otros \\
\hline Ritonavir & Ciclosporina \\
Indinavir & Teofilina \\
Amprenavir & Carbamazepina \\
Nelfinavir & Diltiazem \\
& Verapamil \\
& Dexametasona \\
& Omeprazol \\
& Bromocriptina
\end{tabular}

go es capaz de generar diversas sustancias, entre las que se encuentran: ergotamina, histamina, ácido lisérgico, tiamina, acetilcolina, entre otras. Existen reportes literarios de la edad media donde se describen epidemias caracterizadas por individuos con miembros ennegrecidos que recordaban la carbonización por fuego y que causaban en las víctimas intensa sensación de ardor. La entidad fue nombrada "fuego santo" o "fuego de San Antonio", ya que los enfermos peregrinaban al santuario de San Antonio Ermitaño. Posteriormente se llegó a la conclusión de que la enfermedad era debida a la ingesta de pan amasado con harina de centeno contraminada con el hongo. En 1818, Desganger fue el primer médico en utilizarlo para cuidados obstétricos y en 1822 Hasak reportó que podía ser utilizado en el tratamiento de la hemorragia posparto. Desde 1950 los derivados del ergot se utilizan casi exclusivamente para el tratamiento de cefaleas migrañosas ${ }^{(2)}$. Actualmente el ergotismo que se produce por ingerir directamente el hongo contaminante de los cereales es extremadamente infrecuente, presentándose el síndrome ergotamínico como reacción adversa producida por los derivados del ergot en el tratamiento de la cefalea migrañosa principalmente ${ }^{(3)}$.

Los alcaloides del ergot provienen del componente tetracíclico 6-methyl ergoline. Presentan pobre absorción vía oral además de baja biodisponibilidad, dado por el primer paso metabólico hepático y la excreción biliar que en el caso de la ergotamina alcanza a 90\%. La ergotamina muestra por esta vía un pico de concentración en plasma entre los 45 y 60 minutos y un tiempo de vida media de entre 1,6 y 6,2 horas. El efecto vasoconstrictor 
puede durar 24 a 48 horas. Presentan amplia variedad de efectos farmacológicos destacándose el agonismo y antagonismo de receptores alfadrenérgicos, dopaminérgicos y serotoninérgicos, así como también un efecto directo sobre receptores del músculo liso, especialmente los aminoalcaloides. El estímulo de receptores alfadrenérgicos es responsable de la vasoconstricción periférica al unirse de forma casi irreversible, por lo que la utilización de antagonistas tiene escaso efecto para contrarrestarla. También generan efecto simpaticolítico central, producido por efecto directo del fármaco en centros vasomotores medulares ${ }^{(4)}$.

Frente a un paciente con infección por VIH bajo TARV es importante considerar las interacciones farmacológicas. Algunos de estos fármacos son potentes inhibidores del complejo enzimático citocromo P4503A4, por lo cual se debe prestar especial atención a las interacciones farmacológicas de tipo inhibición enzimática (tabla 1). El citocromo $\mathrm{P} 450$ y principalmente la isoenzima CYP3A4 son responsables del metabolismo de la ergotamina al igual que muchos otros fármacos. Su inhibición produce aumento del nivel sérico de ergotamina con el consiguiente aumento del riesgo de reacciones adversas incluso a bajas dosis $^{(5)}$. Los inhibidores de la proteasa (IP) son potentes inhibidores de la isoenzima CYP3A4; entre ellos, el ritonavir ha sido reportado como el más potente inhibidor de la CYP3A4, actuando en la isoenzima presente en hígado, intestino e incluso en otros sitios. Forma parte del esquema antirretroviral no como droga activa, sino como reforzador de los otros IP utilizando su capacidad de fuerte inhibidor del metabolismo de estos, lo que permite lograr niveles suficientes de IP que aseguren un adecuado control virológico del $\mathrm{VIH}^{(6)}$.

La incidencia estimada de ergotismo en pacientes que consumen ergotamina es de 0,5 por 100.000 habitantes/año ${ }^{(6)}$. El efecto tóxico más importante es la vasoconstricción. Habitualmente afecta a vasos de mediano calibre de las extremidades, menos frecuentemente puede provocar vasoespasmo en otras regiones como coronarias y lecho esplácnico. Se manifiesta clásicamente desde el punto de vista clínico como ergotismo convulsivo o gangrenoso, aunque el origen es común al vasoespasmo ${ }^{(7)}$. El ergotismo gangrenoso se caracteriza por disminución o ausencia de pulsos, palidez, frialdad, dolor y cianosis, pudiendo aparecer flictenas. Evoluciona a la gangrena seca y eventual autoamputación. El compromiso es simétrico generalmente y afecta más frecuentemente los MMII. El ergotismo convulsivo se presenta con contracturas musculares, contracciones involuntarias de miembros, trastornos de sensibilidad, hasta crisis tonicoclónicas generalizadas, coma y muerte en los casos más graves.

El diagnóstico de ergotismo requiere de alta sospecha clínica y una anamnesis minuciosa. Dada la poca frecuen- cia de esta patología y la ausencia de estudios paraclínicos patognomónicos se presenta como un diagnóstico de exclusión. Presenta características clínicas similares a otras enfermedades, entre las que se incluyen la enfermedad aterosclerosa oclusiva, la enfermedad tromboembólica, las arteritis, la displasia fibromuscular y otras enfermedades que se acompañan de vasoespasmo, como el fenómeno de Raynaud, entre otros. Como herramientas diagnósticas de vasoespasmo contamos con ecografía Doppler arterial y arteriografía. Las alteraciones encontradas en el Doppler son vasoespasmo arterial difuso y reducción o ausencia de flujo en la vasculatura afectada ${ }^{(8)}$. La semiología angiográfica del ergotismo fue descrita por Bagby y Cooper en 1972, destacando: simetría lesional; escasa circulación colateral; ralentización de la corriente sanguínea; estrechamientos espásticos lesionales; imágenes de punta de lápiz; menor espasticidad en ramificaciones que en los troncos principales e íntima lisa sin lesiones orgánicas ${ }^{(9)}$.

No existe actualmente un antídoto específico conocido. La terapéutica actual se basa en reportes de casos, por lo que el tratamiento es fisiopatológico en vistas a la reperfusión tisular, la tromboprofilaxis y la suspensión de la ergotamina como primer escalón terapéutico. Entre los fármacos vasodilatadores a utilizar destacamos el nitroprusiato de sodio, de elección en ergotismo severo por su potente efecto vasodilatador arterial directo. Este fármaco debe administrarse en infusión continua y con estrecha vigilancia hemodinámica, ya que puede generar hipotensión arterial severa. Otros efectos adversos son cefaleas, vómitos, diaforesis, taquicardia y malestar subesternal que desaparecen con la suspensión de la infusión. La administración a altas dosis en presencia de insuficiencia hepática o renal puede generar intoxicación por cianuro. La dosis recomendada inicial es $0,5 \mu \mathrm{g} / \mathrm{kg} /$ minuto que se irá titulando según respuesta y hasta una dosis de $10 \mu \mathrm{g} / \mathrm{kg} /$ minuto como dosis máxima. La infusión debe protegerse de la luz y descartarse cada cuatro horas.

En casos de ergotismo moderado, los bloqueadores de canales de calcio como la nifedipina son los fármacos de elección. En nuestro medio, Acle y colaboradores ${ }^{(10)}$ trataron tres casos de ergotismo moderado con $30 \mathrm{mg}$ de nifedipina vía oral cada ocho horas durante diez días con excelente resultados. La prazosina, bloqueante selectivo de los receptores alfa-1 adrenérgicos, también es una droga a considerar, presentando un efecto comparable al nitroprusiato, pero con el beneficio de que puede administrarse por vía oral y no requiere monitoreo continuo de presión arterial. Otros fármacos que se han reportado como vasodilatadores efectivos son prostaglandina E1, prostaciclina y nitroglicerina.

Como tromboprofilaxis durante los períodos de espasmo vascular está formalmente indicada la heparina de bajo peso molecular. También se reporta el uso de antiagregan- 
tes plaquetarios desde la fase aguda y manteniéndose durante tres a seis meses según evolución clínica. La pentoxifilina tendría indicación al disminuir la viscosidad sanguínea, aumentar la deformabilidad eritrocitaria, inhibiendo la agregación eritrocitaria y plaquetaria y por disminuir los niveles de fibrinógeno e inhibir la adhesión de los leucocitos al endotelio. Como opción de rescate frente a pacientes con ergotismo severo en los que se constate una trombosis arterial masiva e inminente gangrena se considerará el uso de fibrinolíticos ${ }^{(11)}$.

El tratamiento quirúrgico de revascularización no se considera inicialmente, ya que es un procedimiento agresivo, sin base fisiológica clara y capaz de generar lesiones intimales comprometiendo aun más la evolución. Tampoco se considera el bloqueo simpático mediante anestesia epidural ni simpatectomía, por estar la vasoconstricción ergotamínica ligada a una acción periférica de receptores adrenérgicos posganglionares y a la actividad directa sobre el músculo liso ${ }^{(6)}$. Será necesaria la terapéutica quirúrgica en casos de necrosis acral delimitada con el objetivo de amputar o realizar exéresis del tejido desvitalizado.

\section{Conclusión}

El ergotismo es una enfermedad poco frecuente que requiere un alto índice de sospecha para su diagnóstico. Actualmente la mayor parte de los casos reportados se deben al abuso farmacológico de los derivados del ergot e interacciones farmacológicas, siendo los pacientes VIH bajo tratamiento antirretroviral un grupo de riesgo vinculado a la asociación de ergotamina con inhibidores de la proteasa. Es importante promover el uso racional de la ergotamina y evitar la automedicación, fomentada por la venta sin prescripción médica y escasa información. Un diagnóstico precoz y retiro del fármaco son medidas terapéuticas fundamentales, no existiendo claro consenso en el resto del tratamiento, si bien la administración de vasodilatadores arteriales y la antiagregación son estrategias habituales en el tratamiento de estos pacientes, relegando los procedimientos invasivos por riesgo de complicaciones y pobre fundamento fisiopatológico.

\section{Resumo}

O ergotismo é uma síndrome clínica pouco frequente, porém potencialmente letal vinculado à intoxicação aguda ou crônica pelo uso de alcalóides do Ergot no tratamento da enxaqueca. Caracteriza-se por um vaso espasmo severo generalizado que pode gerar isquemia periférica ou visceral e levar a disfunção orgânica múltipla e morte. Existem múltiplos fármacos de metabolismo hepático que podem alterar a metabolização da ergotamina podendo alcançar concentrações tóxicas inclusive em doses baixas. Apresentamos o caso de um paciente infectado com vírus da imunodeficiência humana recebendo tratamento antirretroviral que incluía inibidores da protease e que se automedicou com ergotamina. O paciente apresentou posteriormente sintomatologia sensitiva motora deficitária de membros superiores e inferiores, acompanhada de elementos de hipoperfusao distal severa. Solicitou-se Doppler arterial que mostrou vaso espasmo dos eixos arteriais de membros. Realizou-se diagnóstico de ergotismo secundário à associação ergotamina - ritonavir, e transferiu-se o paciente a cuidados intensivos. Iniciou-se tratamento com a suspensão de ambos os fármacos, vasodilatação arterial com nitroprussiato e antiagregaçao com ácido acetilsalićlico. Apresenta-se uma revisão do mecanismo de toxicidade da ergotamina, suas interações farmacológicas, seu diagnóstico e os tratamentos disponíveis para esta patologia.

\section{Bibliografía}

1. Pastur L, Milano Gil A. Ergotamina e inhibidores de la proteasa, impacto clínico de las interacciones farmacológicas: presentación de dos casos. Actual SIDA 2014; 20(5):1-4.

2. Jason Chu. Antimigrainemedications. En: Nelson L, Lewin N, Howland M, Hoffman R, Goldfrank L. Goldfrank's toxicologic emergencies. 9 ed. New York: McGraw-Hill, 2011:763-70.

3. Cisneros J, Jauregui L, Rojas G. Insuficiencia arterial aguda por ergotismo. An Med (Mex) 2008; 53(4):202-10.

4. Sanders-Bush E, Mayer SE. Agonistas y antagonistas del receptor de 5-HT. En: Brunton LL, Lazo JS, Parker KL. Goodman y Gilman: las bases farmacológicas de la terapéutica. 11 ed. México: McGraw-Hill; 2007:305-11.

5. Ayarragaray JE. Ergotism: a change of persepective. Ann Vasc Surg 2014; 28(1):265-8.

6. Finn B, Vadalá S, Meraldi A, Bruetman J, Martínez J, Young P. Ergotismo y HIV. Medicina (B. Aires) 2013; 73(4):346-8

7. Enríquez E, Rangel A, Velasco C, Basave M, López R. Ergotismo por autolimitación. Arch Inst Cardiol Mex 2000; 70(6):603-8

8. Liegl C, McGrath M. Ergotism: case report and review of the literature. Int J Angiol 2016; 25(5):e8-11.

9. Cairols M, Giménez A, Sieyro F, Miralles M. Intoxicación ergotamínica: dos casos de isquemia periférica. Angiología 1991; 43(4):148-52.

10. Acle S, Roca F, Vacarezza M, Álvarez A. Ergotismo secundario a la asociación ergotamina-ritanivir: a propósito de 3 casos. Rev Méd Chile 2011; 139(12):1597-600.

11. Dilmé J, Barreiro J, Yeste M, Escudero J, Llagoslera S, Mestes J, et al. Ergotismo revisión de bibliografía. Angiología 2003; 55(4):311-21. 